Escuela de Ciencias Sociales y Humanidades, UNED, Costa Rica https://revistas.uned.ac.cr/index.php/espiga ISSN: 1409-4002 • e-ISSN: 2215-454X

\title{
Relación de la humanidad con la naturaleza, las perturbaciones y el turismo
}

\section{Humanity's Relationship with Nature, Disturbances and Tourismand}

Le rapport entre l'être humain, la nature, les perturbations et le tourisme

L. Ana Guzmán*, Luis E. Tuninetti** y Dafne Mizdraje***

Recibido: 19 de febrero de 2021 • Aceptado: 10 de diciembre de 2021

* Doctora en Ciencias Geológicas, Universidad Nacional de Río Cuarto, de Argentina. Ingeniera en Ecología, Universidad de Flores, de Argentina. Docente en el Instituto del Rosario, de Argentina, y en el Instituto Académico Pedagógico de Ciencias Básicas y Aplicadas, de la Universidad Nacional de Villa María, de Argentina. Directora del Centro de Estudios de ordenamiento Ambiental del Territorio e investigadora en el Grupo Periurbano y Ordenamiento Territorial, de la Universidad Nacional de Villa María, de Argentina. Coordinadora del Grupo periurbano del programa integración con la comunidad, financiado por el Ministerio de Agricultura de la provincia de Córdoba, Argentina (20202021). Directora del proyecto de extensión 17 Objetivos de Desarrollo Sostenible, de la Región Centro del Departamento General San Martín (2019-2020). Correo: Iguzman@gmail.com 
** Doctorando en Ciencias Sociales, Universidad Nacional de Villa María (UNVM), de Argentina. Magister en Evaluación de Impacto Ambiental, Instituto de Investigaciones Ecológicas de Málaga, España. Docente en el Instituto Académico Pedagógico de Ciencias Básicas y Aplicadas, de la Universidad Nacional de Villa María, de Argentina. Coordinador del Observatorio Regional de Cambio Climático, UNVM. Director del proyecto de investigación Condiciones Climáticas en las dimensiones territoriales de la región del conglomerado Villa María-Villa Nueva (2020-2021). Correo: tuninetti.ma@gmail.com

*** Doctoranda en Desarrollo Territorial, Universidad Nacional de Río Cuarto. Becaria doctoral del CIT Villa María-CONICET, Centro de Investigación y Transferencia Conicet-Universidad Nacional de Villa María (UNVM), de Argentina), especializada en Servicios Ambientales y Ordenamiento Territorial, UNVM. Licenciada en Desarrollo Local-Regional, Instituto Académico Pedagógico de Ciencias Sociales, de la UNVM. Investigadora en el proyecto Diagnóstico integral en el periurbano de las ciudades intermedias en el área central del Departamento General San Martín. Miembro del programa Integración con la comunidad, financiado por el Ministerio de Agricultura de Córdoba, Argentina (2020-2021). Correo: dafne.mizdraje1991@gmail.com 


\section{Resumen}

La relación de la humanidad con la naturaleza evolucionó con las perturbaciones y el equilibrio como elementos clave. Este trabajo analiza la perturbación como un aspecto que distancia a la sociedad de la naturaleza y el rol del turismo, esto por medio del análisis documental de hechos en la historia y del conocimiento en la temática. Como resultados, se obtuvo que las formas de conciencia y de vinculación fueron parte de la destrucción de la naturaleza, llevando a la extinción de especies, fragmentación de los ecosistemas y deterioro de la calidad ambiental. En relación con el turismo, presenta una dualidad por lo cual pueden degradar los ecosistemas o establecer áreas para conservación. Esto lleva al planteo de que en el actual contexto deben replantearse las formas de vinculación y revalorizar los conocimientos y necesidades del territorio.

Palabras clave: Ambiente, desarrollo, sociedad, sustentabilidad

\section{Abstract}

This Humanity's relationship with nature evolved with disturbances and balance as key elements. This article analyzes disturbance as an aspect that creates distance between society and nature and the role of tourism; this is done through documentary analysis of facts in history and knowledge of the subject. In consequence, it was obtained that the forms of awareness and bonding were part of the destruction of nature, leading to the extinction of species, fragmentation of ecosystems and deterioration of environmental quality. In relation to tourism, a duality exists in which ecosystems can be degraded or areas of conservation can be established. This leads to the proposition that in the current context, forms of relationship must be reconsidered and the knowledge and needs of the territory revalued.

Keywords: Environment, development, society, sustainability.

\section{Résumé}

La relation de l'humanité avec la nature a évolué avec les perturbations et l'équilibre en tant qu'éléments clés. Ce travail étudie à travers l'analyse documentaire des faits dans I'histoire et des connaissances sur la thématique, la perturbation comme un aspect qui éloigne la société de la nature et du rôle du tourisme. Les résultats ont constaté que les manières de conscience et de créer des liens ont fait partie de la destruction de la nature, ce qui a contribué à la disparition d'espèces, à la fragmentation des écosystèmes et à la dégradation de la qualité de l'environnement. En ce qui concerne le tourisme, on trouve qu'il y a une dualité où les écosystèmes peuvent être dégradés, ou bien des zones de conservation sont établies; cela entraîne à repenser et à redéfinir les manières d'établir des liens, ainsi que de revaloriser les connaissances et les besoins des territoires.

Mots-clés: Environnement, développement, société, durabilité. 


\section{Introducción}

La relación que tiene la humanidad con la naturaleza, su historia, las ciencias en el tiempo y su evolución son fundamentales para la comprensión del contexto actual y los procesos que llevan a la degradación del ambiente, así como de la búsqueda de alternativas que permitan vislumbrar un horizonte positivo posible. Desde finales de la década de 1960 y comienzos de la década de 1970, el pensamiento ambiental y la identificación de la pérdida de la naturaleza fue tomando cuerpo e identidad, tal como se puede observar en la publicación del Informe Bruntland ${ }^{1}$ en 1987. Seguidamente, las diferentes cumbres de la Tierra e investigaciones han demostrado cómo no ha mermado la pérdida de la naturaleza, como lo evidencian los informes del Programa de las Naciones Unidas para el Medio Ambiente (PNUMA), de la Organización de las Naciones Unidas (ONU).

Por ello, todas las actividades en sus diferentes medidas y el modelo de desarrollo predominante deben buscar cambios radicales en cuanto a la relación con los ecosistemas, así como los Estados implementar políticas que permitan el aprovechamiento sin perjudicar a la naturaleza. En este sentido, la actividad turística no se presenta como una excepción. El turismo masivo, por sus características, ha llevado a los límites de carga a los ecosistemas de acogida, situación que amerita presentación de propuestas y alternativas como el turismo sustentable, turismo de naturaleza y el ecoturismo que se posicionan como posibles salidas.

Distintos autores ${ }^{2} 3$ evaluaron los impactos ambientales que la actividad turística genera de forma puntual, mientras que el resumen «Cambio climático y turismo: responder a los retos mundiales» ${ }^{4}$ estableció, a modo general, tres grandes grupos emisores de gases de efecto invernadero que contribuyen al cambio climático; entre ellos, uno de los elementos de mayor importancia se encuentra el traslado aéreo de personas para su recreación ${ }^{56}$, además se agrega el uso de combustibles para industrias y la ganadería.

En el transcurso del tiempo, la humanidad se vinculó de diferentes formas con los ecosistemas, donde la percepción de sí misma y de los otros seres fue

\footnotetext{
${ }^{1}$ Informe de Brundtland 'Our Common Future', 1987, https://web.archive.org/web/20111201061947/http:// worldinbalance.net/pdf/1987-brundtland.pdf

2 María García Hernández, «Turismo y Medio Ambiente», en Ciudades históricas. De la capacidad de acogida turística a la gestión de los flujos de visitantes, Anales de Geografía de La Universidad Complutense (2000):

131-148, https://core.ac.uk/download/pdf/38823161.pdf

${ }^{3}$ Constanza Barrera y Romina Bahamondes, «Turismo sostenible: Importancia en el cuidado del medio ambiente», RIAT: Revista Interamericana de Medioambiente y Turismo 8, n. ${ }^{1}$ (2012): 50-56, https:// dialnet.unirioja.es/servlet/articulo?codigo $=4052116 \&$ info=resumen\&idioma=ENG

${ }^{4}$ Programa de las Naciones Unidas para el Medio Ambiente, «Cambio climático y turismo: Responder a los retos mundiales», 2007. Declaración de Davos. https://www.ucipfg.com/Repositorio/MGTS/MGTS14/MGTSVCC/modulo2/Declaracion_de_Davos._Cambio_Climatico_y_Turismo.pdf

${ }^{5}$ Ibíd.

${ }^{6}$ Manfred Lenzen, Ya-Yen Sun, Futu Faturay, Yuan-Peng Ting, Arne Geschke y Arunima Malik, «The Carbon Footprint of Global Tourism», Nature Climate Change n. ${ }^{\circ} 6$ (2018): 522-28, https://doi.org/10.1038/s41558-0180141-x
} 
cambiando. En este sentido, las acciones de la humanidad tuvieron también su construcción, así se llegó a disociar al ser humano de la naturaleza. Este acto de separación plantea el esquema en el cual la naturaleza podría funcionar sin la humanidad y que los humanos solamente interactuarían por medio de sus acciones e incrementan las perturbaciones negativas ${ }^{7}$.

Al considerar dicha afirmación, la perturbación es concebida como el resultado de una acción que modifica o altera el estado de equilibrio de un entorno sistémico abierto; por ende, los «procesos ajenos o perturbaciones» de un ecosistema particular son aquellos que modifican las situaciones estáticas dentro del ecosistema. Las perturbaciones no poseen connotación positiva o negativa, eso es en función de los sujetos sociales, contexto y fines en los cuales se establecen las variables. La valoración de la naturaleza no siempre es económica, por lo cual no puede siempre ser trasladada a un precio monetario cuando se genere un deterioro de la naturaleza por una perturbación negativa para los ecosistemas ${ }^{8}$, aunque sí es necesario reconocer que su mercantilización constituye una práctica común por parte de los actuales sistemas de gestión ambiental. No obstante, establecer el valor de la perturbación y reconocer desde qué marco se realiza resulta de vital importancia. La interiorización de este aspecto de las perturbaciones sin una debida contextualización puede resultar muy peligroso, ya que acaba por simplificar un concepto que puede servir de fundamentación para el extractivismo, que, en palabras de Gudynas ${ }^{9}$, es un modelo de desarrollo basado en la apropiación de la naturaleza que enriquece un entramado productivo dominante, principalmente por multinacionales, con la consecuente generación de erosión social y ambiental. Esta condición, donde el capitalismo se despliega como un sistema que realiza extracciones excesivas, ha permitido un deterioro profundo de la naturaleza.

Con el fin de comprender las perturbaciones, se resalta la necesidad de respetar la coexistencia de la totalidad de los seres vivos y sus entornos, al llevar la discusión hacia aspectos éticos que generaron nuevas corrientes de pensamientos como, por ejemplo, la ecología profunda ${ }^{10}$; en este sentido, la relevancia sobre el lugar que ocupa la sociedad es equitativa con los otros organismos vivos. A esta teoría las sucedieron otras que cambiaron la visión eurocentrista para desarrollar visiones más territoriales y desde multiniveles ecológicos, económicos y culturales ${ }^{11}$. Asimismo, otras corrientes ponen en jaque

\footnotetext{
7 Roberto Carlos Rodríguez Caro, «Estudios sobre los efectos de las perturbaciones ambientales en poblaciones animales mediante métodos analíticos y de simulación», Universidad Miguel Hernández, 2017, http://dspace.umh.es/bitstream/11000/5170/1/Tesis Rodriguez-Caro\%2C Roberto Carlos.pdf; E. P. Odum, Ecología, ed. Editorial Interamericana (México, 1972).

8 Margarita Nieto, Luisa Fernanda Cardona y Catherine Agudelo, Servicios ecosistémicos: Provisión y regulación hídrica, En Los Páramos (Bogotá: Instituto Bogotá, 2015).

${ }^{9}$ Eduardo Gudynas, «Diez tesis urgentes sobre el nuevo extractivismo. Contextos y demandas bajo el progresismo sudamericano actual», en Extractivismo, politica y sociedad, 187-225 (Quito: Centro Andino de Acción Popular y Centro Latino Americano de Ecología Social, 2009), 187-225.

10 Arne Naess, Une Écosophie Pour La Vie. Introductión à l'écologie Profonde, Du Seuil (París, 2017).

11 Arturo Escobar, «Territorios de Diferencia:La ontología política de los derechos al territorio» en: Cartografías de la paz : una mirada crítica al territorio / comp. Diego Andrés Mora Arenas, Natalia Sánchez Corrales. Bogotá: Ediciones Unisalle, 2014 (Colombia, 2010), https://ciencia.lasalle.edu.co/cgi/viewcontent.cgi? article $=1005 \&$ context $=$ catedra_lasallista\#page $=108$
} 
la dualidad entre humanidad-naturaleza y centralizan el análisis en torno a las dinámicas que caracterizan a los más diversos sistemas socioeconómicos, en la cual los aspectos políticos y culturales cobran mayor relevancia al interpretar las perturbaciones ${ }^{12}$.

De acuerdo con estas posiciones, por un lado se propone analizar la perturbación como un elemento que distancia la sociedad de la naturaleza y establecer el rol del turismo en este contexto, así como las herramientas implementadas comúnmente para medir la perturbación (como impactos ambientales). Por otro lado, realizar una identificación primaria de las variables y factores que hacen a lo ambiental, para luego plantear la vinculación con la sociedad a través de la actividad del turismo masivo.

Para lograr lo anterior, el trabajo se ampara en el proceso metodológico de Hernández Sampieri et al. ${ }^{13}$, quien se sitúa en una perspectiva constructiva y permite establecer preguntas disparadoras para la reconstrucción teórica de los objetos de estudio: ¿Qué son las perturbaciones? ¿Qué es el equilibrio ecológico? ¿Cómo se relaciona el humano con la naturaleza? ¿Siempre fue igual? ¿La fragmentación del conocimiento y de la naturaleza están vinculados? Para dicho análisis de conceptos y variables se optó por el desarrollo de técnicas documentales, al trabajar con antecedentes relacionados a los elementos de estudio que vincula sus orígenes conceptuales como, por ejemplo, principales corrientes del pensamiento vinculadas con la relación humanidad-naturaleza y su desarrollo en el tiempo.

Se tomaron fuentes de información primaria y secundaria en soporte impreso y digital para identificar los enunciados que determinan los conceptos de turismo de naturaleza, ecoturismo e impactos ambientales. Asimismo, se tomaron documentos de instituciones internacionales como los elaborados por el PNUMA, la Organización Mundial para el Turismo (OMT) y convenios internacionales como la Declaración de Québec (2002), las Metas de Aichi (2010) y los 17 Objetivos para el Desarrollo Sostenible, así como autores de referencia en las disciplinas que estudian el ambiente. No obstante, es necesario aclarar que desde esta perspectiva, las preguntas disparadoras se reformulan y se fueron generando nuevas interrogantes que llevaron a determinar las formas de evaluación.

Desde ese lugar se consideraron las herramientas más utilizadas y citadas en las publicaciones asociadas a los objetos de estudio, para ser analizadas desde su construcción y contexto de formación, las cuales fueron Capacidad de carga, Estudio de impacto ambiental y Evaluación ambiental estratégica. Además, se tomaron situaciones reales vinculadas con el turismo y su articulación con las herramientas previamente citadas, como el caso del Tren Maya, en México, y la iniciativa mundial sobre turismo y plástico. Finalmente, a partir de un proceso deductivo concatenado, se establecen conclusiones respecto a los conceptos y

\footnotetext{
12 Enrique Leff, «Saber Ambiental: Sustentabilidad, Racionalidad, Complejidad, Poder» (Ciudad de México: Siglo XXI, 2002)

13 Roberto Hernández Sampieri, Carlos Fernández Callado y Pilar Baptista Lucio, Metodología de la investigación (Ciudad de México: McGraw Hill, 2014).
} 
herramientas que dan cuerpo a la relación de la humanidad con la naturaleza, las perturbaciones y el turismo.

\section{Desarrollo}

El ser humano, en su proceso histórico tuvo diferentes formas de racionalizar a la naturaleza, su vinculación y su rol con ella o en ella14; a grandes rasgos, se puede establecer que, con el paso de miles de años la relación con la naturaleza, fue mutando, en sus comienzos con una relación mayoritariamente de coexistencia, para luego pasar a ser, la naturaleza, un objeto, llegando al momento en que la conciencia racional pasó a tomar el rol principal en el pensamiento, con la diferenciación del ser humano con la naturaleza ${ }^{15}$.

En este sentido, Ortíz Blanco ${ }^{16}$, en su línea de tiempo y a partir de las visiones filosóficas, destaca que Platón desarrolla la visión de la relación ser humanonaturaleza, la cual incluye la belleza natural y de qué forma esto intervino en el fomento de las costumbres. Aristóteles ofrece definiciones de naturaleza, la cual es transferida a aquello que tiene movimiento y cambio, distinguiéndose de las construcciones inanimadas. El Renacimiento, junto al auge de la ciencia, muestra un gran interés en la naturaleza como objeto de transformación y dominación, acentuando una relación del ser humano-naturaleza como contraposición. Posteriormente, otros filósofos como Kant y Hegel establecen orígenes diferentes para la naturaleza y la humanidad, para el primero es un conjunto de fenómenos en un tiempo y espacio determinado; pero, para el segundo la naturaleza es la materialización del espíritu absoluto.

Los acontecimientos en la época contemporánea denotan cómo la relación ser humano-naturaleza va siendo atravesada por las diferentes ciencias como la matemática y la física ${ }^{17}$. A esto le siguió el entendimiento de la relación de la humanidad y la naturaleza desde la mirada de las ciencias sociales y exactas, que se manifestó dicotómica, distanciando los procesos de investigación ${ }^{18}$, sobresaliendo, en las ciencias exactas, la identificación y estudio de la naturaleza desde sus usos y servicios.

Sumado a estos procesos de racionalización y vinculación con la naturaleza, los modelos de desarrollo imperantes fueron acentuando aún más una brecha entre

\footnotetext{
14 Eugenio Raúl Zaffaroni, La Pachamama y el humano (Buenos Aires, Colihue, Madres de Plaza de Mayo, 2011).

15 Gilberto Romero y Andrew Maskrey, «Como entender los desastres naturales en los desastres no son naturales», en Los desastres no son naturales, ed. Red de estudios sociales en prevención de desastres en América Latina, 1993, 140. https://repositorio.gestiondelriesgo.gov.co/bitstream/handle/20.500.11762/19762/ LosDesastresNoSonNaturales\%28Maskrey_1993\%29.pdf?sequence=1\&isAllowed=y

16 Mercedes Adriana Ortiz Blanco, «La relación hombre-naturaleza. Tendencias de su filosofar en Cuba», Revista de Ciencias Sociales, n. 32 (Chile, 2014): 63-76, https://www.redalyc.org/pdf/708/70831715004.pdf. 17 Ibíd.

18 Jorge Pardón Acosta y Dariel Bermúdez, «De las 'Ciencias Duras' y las ‘Ciencias Blandas», Revista Caribeña de Ciencias Sociales, n. ${ }^{2}$ 2019-10 (2019): 1-12, https://www.eumed.net/rev/caribe/2019/10/cienciasduras-blandas.htmllbíd., 115.
} 
la naturaleza y la sociedad19, lo cual generó, por medio de los procesos de extracción de recursos y explotación, pérdidas importantes en la biodiversidad del planeta, que afectan directa e indirectamente al desarrollo de la sociedad 2021.

En relación con ello, y puntualizando en los aspectos conceptuales referidos a las «perturbaciones de la naturaleza», se considera prioritario dar cuenta del concepto de «equilibrio» y la teoría del caos.

En principio, el concepto de equilibrio se aplica en la ecología como un proceso en el cual existe la homeostasis, donde aquellos pequeños cambios que puedan sucederse son balanceados por medio de la retroalimentación negativa, así se lleva al sistema de nuevo a su punto de equilibrio original22. Dicho en otras palabras, el equilibrio ecosistémico cuenta con un estado clímax, en el que los procesos ecológicos se dan de tal forma que no existen excesos; cada acción corresponde a un proceso determinado y establecido, resultantes de una sucesión y vinculación entre diferentes comunidades y poblaciones. Este equilibrio consiste en que cada cambio que puede suceder al interior del ecosistema, puede ser revertido por una fuerza reparadora que lo vuelve a su estado original; en el caso de que eso no se pueda recuperar, se rompe ese equilibrio, lo que lleva a ese ecosistema a otro estado diferente, generalmente de menor diversidad y complejidad.

Desde la ecología, para comprender los procesos ecosistémicos y los cambios que en estos se sucedían, se confeccionaron diferentes teorías, entre ellas la teoría del caos. Esta teoría establece que no es posible la predicción por medio de la acumulación de las interacciones entre los componentes, en contraposición a la propuesta del equilibrio. La teoría del caos propone que todos los sistemas alcanzan un umbral, el cual, al ser superado, lleva al sistema a otro nivel de organización; este proceso se define por cambios bruscos que ocurren por un conjunto nuevo de interacciones emergentes; una organización, donde el manejo de la materia y energía presentes en el sistema es clave ${ }^{23}$.

Esta teoría forma parte de las teorías de los sistemas complejos ${ }^{24}$, donde estos no son deterministas ni lineales, lo que hace más complejas e inciertas las respuestas de los sistemas ecológicos. Si bien el recorte de un sistema es necesario para ser estudiado, lo que implica la reducción de variables a

\footnotetext{
19 Arturo Escobar, La invención del Tercer Mundo: Construcción y deconstrucción del desarrollo (Caracas: Editorial el perro y la rana (Caracas, Venezuela, 1998)., «La literatura y la música...», 85-98.

20 José Nicolás Pérez-García, «Causas de la pérdida global de biodiversidad», Revista de la asociación colombiana de ciencias biológicas 1, n. ${ }^{\circ} 32$ (2020): 183-98, https://doi.org/10.47499/revistaaccb.v1i32.219 ${ }^{21}$ Juana R. Figueroa, «El hombre, clave fundamental en el desarrollo» Espacio Abierto 15, n. ${ }^{\circ}$ (2006): 597616, https://www.redalyc.org/pdf/122/12215306.pdf.

22 Eugene P. Odum, Ecología, ed. Editorial Interamericana (México, 1972).

${ }^{23}$ Carlos M. Madrid Casado, «Historia de la teoría del caos contada para escépticos: Cuestiones de génesis y estructura», Ed. Encuentros Multidisciplinares 34 (2010): 1-15 https://repositorio.uam.es/handle/ 10486/679228., 2.

24 Rolando García, Sistemas complejos, conceptos, método y fundamentación epistemológica de la investigación interdisciplinaria (Barcelona: Gedisa, 2006).
} 
constantes en un momento dado, esto dista de lo que en realidad ocurre en los sistemas naturales, ya que pequeñas variaciones suceden todo el tiempo. Este análisis de la complejidad de los ecosistemas, donde los cambios en diferentes escalas y magnitud no cuentan con respuestas predecibles reales, pone en jaque a las intervenciones que se desean realizar en los ambientes naturales, con el resultado de que, en la gran mayoría ejemplos, estos han sido desfavorables para la biodiversidad 25 .

La humanidad, en esta interpretación e interacción con los ecosistemas, se ve atravesada por su misma evolución 2627 . El desarrollo del pensamiento científico y las diferentes corrientes fue dando funciones a la humanidad para protegerlos y mantenerlos en equilibrio, bajo la condición de utilidad, lo que se sustenta en un sistema de valores que depende de la sociedad en su contexto temporal. Esto es más subjetivo al dar lugar y sostener el equilibrio de algunos ecosistemas como más importantes para algunos y menos para otros ${ }^{28}$. Esta construcción se acentuaba frente a las desigualdades sociales y los intereses económicos predominantes, los cuales se fueron tensando y redefiniendo, respaldados a partir de las últimas cumbres de la Tierra y la visión de Lovelock ${ }^{29}$ sobre la construcción de la Tierra como un organismo vivo, quien sostuvo que la humanidad es parte de dicho organismo, si bien se puede ser como una célula que forma un tejido, también se puede funcionar como un parásito.

La teoría del caos, por su parte, significó una nueva visión de los «ciclos de la naturaleza» y, paralelamente, se fue dejando fuera a la humanidad, ubicándola como un agente de perturbación negativa, como elemento societario ajeno a la naturaleza, modificando el entorno hacia formas irreconocibles, perdiendo el reflejo en los animales como iconos de fuerza, valor y coraje con los cuales la humanidad se comparaba y pasando a vincularse más con los elementos inertes de su creación. Dado este desarrollo, en el último siglo, con el resurgir de pensamientos y ciencias más vinculadas a las condiciones territoriales, este paradigma del mundo fue mutando y tomó impulso la revalorización y rescate de los saberes ancestrales, impulsando un cambio en el modelo de desarrollo dominante desde un punto de vista epistemológico ${ }^{30} 31$.

\footnotetext{
25 Intergovernmental Science-Policy Platform on Biodiversity and Ecosystem Services (IPBES), 2019 «Summary for Policymakers of the Global Assessment Report on Biodiversity and Ecosystem Services», Bonn, Edición en PDF, https://doi.org/10.5281/ZENODO.3553579.

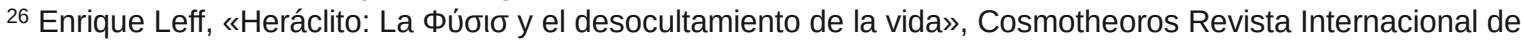
Epistemología Ambiental 1 (2020): 1-38.

${ }_{27}$ Graciela Baldi López y Eleonora García Quiroga, «Calidad de vida y medio ambiente. La psicología ambiental» Universidades (México, DF), n. ${ }^{\circ} 30$ (2005): 9-16, https://biblat.unam.mx/es/revista/universidadesmexico-d-f/articulo/calidad-de-vida-y-medio-ambiente-la-psicologia-ambiental

28 Víctor M. Toledo, «Repensar la conservación: ¿Áreas naturales protegidas o estrategia bioregional?», Gaceta Ecológica, no. 77, 2005, https://www.redalyc.org/pdf/539/53907705.pdf

29 James Lovelock, «La venganza de la Tierra. La teoría de Gaia y el futuro de la humanidad» (Buenos Aires: Planeta, 2007).

30 Martín David Harvey, «Razones para ser anticapitalistas», ed. María Fernanda Pampín et al., Clacso, 2020, Buenos Aires. https://www.tni.org/files/publication-downloads/ razones_para_ser_anticapitalistas_david_harvey_clacso.pdf

31 Boaventura De Sousa Santos, «La cruel pedagogía del virus», ed. María Fernanda Pampín et al., Clacso, 2020, Buenos Aires, https://biblioteca-repositorio.clacso.edu.ar/bitstream/123456789/15543/1/La-cruelpedagogia-del-virus.pdf.
} 
El concepto de equilibrio también está vinculado con la construcción teórica del momento, al período de tiempo con variables establecidas y al grado de importancia que le asigne cada sociedad, en relación con sus valores ${ }^{32}$. No obstante, resultaría imposible que dicho equilibrio sea permanente; autores como Hardin ${ }^{33}$ plantean en «la tragedia de los comunes» que las acciones individuales llevan al colapso del sistema, con consecuencias que acaban por afectar a todas las personas cuando se busca un beneficio a corto plazo en algún elemento impulsados por tensiones económicas, con la noción de perturbación como efecto negativo de la actividad antrópica sobre la naturaleza, al generar pérdida de biodiversidad y destrucción de ambientes naturales.

En este marco, resulta importante ensayar alternativas que pueden cambiar esta percepción en la que priman los intereses individuales y económicos, para minimizar esas perturbaciones. Es ahí donde resulta fundamental encontrar alternativas a actividades como el turismo masivo, el cual satura los ecosistemas, genera desigualdades sociales, desplaza actores locales y fagocitan recursos naturales 3435 .

Esta afirmación se ampara en el proceso que se generó al explorar la articulación entre perturbaciones antrópicas e impactos ambientales. Durante años se fueron explorando formas para medir dichas perturbaciones. En ese sentido, la Evaluación de impacto ambiental es una herramienta metodológica que busca identificar, a partir de las variables que generan modificaciones, el impacto en los factores ambientales, tales como la flora, fauna, agua, suelo y aire; esta herramienta mide el impacto puntual de una perturbación. A pesar de todo, no es eficiente como herramienta única de gestión ambiental debido a la naturaleza abierta y compleja de los ecosistemas, ya que no contempla las relaciones de estos en su conjunto, como ser la presión de otras actividades similares en los mismos ecosistemas. Por ejemplo, un emprendimiento hotelero puede presentar una Evaluación de impacto ambiental, en la que se puede identificar, entre otras cosas, la extracción de agua de las napas freáticas, pero la herramienta no contempla si en ese ecosistema ya existen otras actividades que extraigan agua de dicha napa; por lo que se puede llegar a decir que el emprendimiento tendrá un bajo impacto, pero para el sistema natural será un elemento más que en conjunto puede llevar al límite del recurso en cuestión.

Otra herramienta de medición es la capacidad de carga, a través de la cual se analiza la cantidad de turistas que el sistema puede soportar. Este concepto, que proviene de la ecología, es entendido como la densidad o abundancia de individuos que pueden hacer uso u ocupar un sistema sin causar un impacto negativo. En términos de crecimiento poblacional, es una densidad de individuos

\footnotetext{
32 Maribel Osorio García, «Turismo masivo y alternativo. Distinciones de la sociedad moderna/posmoderna», Convergencia. Revista de Ciencias Sociales 17, n. 52 (2010): 235-260, http://www.scielo.org.mx/pdf/conver/ v17n52/v17n52a10.pdf.

33 Garrett Hardin, «The Tragedy of the Commons», Science 162, 1968.

${ }^{34}$ Alfredo A. César Dachary, Stella Maris y Arnaiz Burne, «Turismo masivo o alternativo: Los límites de la sustentabilidad», Terra Mundus 1, n. ${ }^{\circ} 1$ (2014). http://dspace.uces.edu.ar:8180/jspui/handle/123456789/2870 35 Francisco Rodríguez Martínez, «El Impacto Ambiental Del Turismo» En Andalucía, Simposio HispanoFrancés Desarrollo Regional y Crisis Del Turismo, 1994.
} 
a partir de la cual la población ya no crece, dado que los recursos no son suficientes ${ }^{36}$ 37. La discusión respecto a este criterio es la transferencia del término capacidad de carga hacia actividades antrópicas para uso turístico. En este sentido, Echamendi Lorente ${ }^{38}$ describe los diferentes conceptos que se construyeron desde el turismo para definir la capacidad de carga, uno de los cuales la define como la cantidad de turistas que un sistema -físico ambiental, económico y cultural- puede soportar. Asimismo, la OMT39 la define como la capacidad máxima de turistas que el sistema puede soportar sin poner en peligro los recursos. En las diversas acepciones se incluyen la satisfacción del turista y los beneficios, además se establecen como variables por considerar, la capacidad de la infraestructura y la carga social percibida, al ignorar el efecto de la actividad turística sobre la flora y fauna. Desde allí, se considera que se ha avanzado en la implementación en diversas áreas, la determinación de las variables, no logran llegar a la sustentabilidad que se manifiesta en los conceptos $^{40}$. En este mismo sentido, Vera Rebollo ${ }^{41}$ establece que los indicadores implementados son insuficientes para aportar información y lograr minimizar los impactos de las intervenciones; por lo tanto, dicha herramienta cuenta con sus limitaciones, por ser una metodología que orienta la capacidad de carga en principio a un valor máximo ${ }^{42}$, cuando debería buscar el valor óptimo; por otra parte, la identificación de las variables de difícil medición e impredecibles, como el cambio climático, no son posibles de incorporar fácilmente y deja fuera aspectos que hacen al sistema complejo ambiental.

La Evaluación ambiental estratégica es una herramienta que posibilita una visión más amplia de los impactos que se generan a nivel sistema. Al estar orientada a políticas, planes y programas que se ejecutan en una región o jurisdicción determinada, más allá que continúe replicando parámetros universales de medición dentro de la racionalidad dominante ${ }^{43}$. Es necesario rescatar que, si bien presenta un análisis de mayor escala, cuenta con recortes, dando peso a

\footnotetext{
${ }^{36}$ Christophe Bonenfant, Jean-Michel Gaillard, Tim Coulson, Marco Festa-Bianchet, Anne Loison, Mathieu Garel, Leif Egil Loe, Pierrick Blanchard, Nathalie Pettorelli, Norman Owen-Smith, Johan Du Toit y Patrick Duncan, «Chapter 5 Empirical Evidence of Density-Dependence in Populations of Large Herbivores», Advances in Ecological Research 41 (2009): 313-357, https://doi.org/10.1016/S0065-2504(09)00405-X

${ }^{37}$ Algunos de los recursos que influyen en el crecimiento son la calidad de suelo, disponibilidad de alimento y agua.

38 Pablo Echamendi Lorente, «La capacidad de carga turística. Aspectos conceptuales y normas de aplicación», Anales de Geografla de la Universidad Complutense 21 (2001): 11-30, https://www.ucm.es/data/ cont/media/www/pag-49173/2001_Artículo Echemendi_Teoría (ANALES).pdf

39 World Tourism Organization (2013), «Sustainable Tourism for Development Guidebook - Enhancing capacities for Sustainable Tourism for development in developing countries», UNWTO, Madrid, DOI: https:// doi.org/10.18111/9789284415496

40 Richard William Butler, «The Concept of Carrying Capacity for Tourism Destinations: Dead or Merely Buried?», Progress in Tourism and Hospitality Research 2, n. ${ }^{\circ} 3-4$ (1996): 283-293, https://doi.org/10.1002/ PTH.6070020309

41 José Fernando Vera Rebollo, «Planificación y gestión del desarrollo turístico sostenible: Propuestas para la creación de un sistema de indicadores» Ed. Instituto Universitario de Geografía Universidad de Alicante (Alicante, 2001), https://rua.ua.es/dspace/bitstream/10045/20506/1/ Planificacion_gestion_sostenible_desarrollo_turistico_sostenible.pdf.

42 María Pilar Flores Asenjo y M. C. Parra Meroño, «Indicadores de capacidad de carga del turismo», Revista de investigación en turismo y desarrollo local 3, n. 8 (2010): 1-15.

43 Domingo Gómez Orea, Mauricio Gómez Villarino y Alejandro Gómez Villarino, «Evaluación ambiental estratégica» (Madrid, 2014), ed. Mundi-Pren.
} 
una actividad en un territorio como elemento de análisis. Asimismo, en muchos casos queda en pronunciamientos derivados de los convenios internacionales, indicadores internacionales, consumo y capital, etc. Esta herramienta fue un avance significativo, ya que su visión está orientada a la gestión que se hace en los ecosistemas, siendo muy prometedora para la integración del turismo.

Todas estas herramientas, las cuales parten de la premisa de regular los impactos negativos, en gran parte se han convertido en herramientas de validación de proyectos de sectores hegemónicos de poder para la concreción de obras de infraestructura 0 de inversiones que, en muchos casos, distan realmente de ser una necesidad de los pobladores locales. Además, los costos que conllevan son altos y, en muchos casos, dejan fuera de las posibilidades de ejecución a varios sectores.

Al considerar los diferentes modelos de desarrollo que se han ido sucediendo en el transcurso de los años y que aportaron a la consolidación del poder económico, han incrementado los impactos ambientales que se evidencian en el incumplimiento de los acuerdos internacionales como la reducción de la emisión de gases de efecto invernadero y los valores de conservación de las Metas de Aichi $(2010)^{44}$.

Un ejemplo de cómo las herramientas administrativas pueden operar para la concreción de megaobras turísticas que cuentan con cuestionamientos sobre su sustentabilidad, es el caso del Tren Maya en México; este fue presentado como una obra insignia del gobierno de Andrés Manuel López Obrador, introducido por el Fondo Nacional de Fomento al Turismo como «un proyecto para mejorar la calidad de vida de las personas, cuidar el ambiente y detonar el desarrollo sustentable»45; en él, según las autoridades de aplicación intervinientes, se han cumplido todos los pasos administrativos requeridos. Cuando se indaga desde otros sectores, resultan demoledoras las críticas al proyecto: organizaciones no gubernamentales y activistas sociales denuncian que con la obra se pondría en peligro hasta 18 especies, entre ellas, algunas emblemáticas, tales como el puma, ocelote y jaguar; se verán afectadas diez áreas naturales protegidas, destrucción irreparable de 1288 sitios arqueológicos, vulnerabilidad de derechos de 146000 indígenas, entre otras perturbaciones de la fastuosa idea; ahora bien, menos del $1 \%$ del presupuesto del proyecto será reservado para la mitigación del impacto ambiental 464748 .

\footnotetext{
44 Biosafety Unit, «Metas de Aichi Para La Diversidad Biológica» (Secretariat of the Convention on Biological Diversity, November 5, 2018), https://www.cbd.int/sp/targets/.

45 Infobae, «Tren Maya: El gran impacto ambiental que dejará a su paso el proyecto insignia de AMLO», 2020, https://www.infobae.com/america/mexico/2020/08/24/tren-maya-el-gran-impacto-ambiental-que-dejaraa-su-paso-el-proyecto-insignia-de-amlo/.

46 Jorge A. Benítez y M. Alexander Shelley, «Evaluación ambiental estratégica (Preliminar) del proyecto Tren Maya», acceso: 18 de enero de 2022, https://www.researchgate.net/publication/331558425 a la indígena. 47 Isabel Clavijo Flórez y Daniel Castrejón, «Análisis Sobre La Protección y Garantía Del Derecho Humano a Un Medio Ambiente Sano En La Región Sureste Mexicana» (Ciudad de México, July 30, 2020), https:// poderlatam.org/wp-content/uploads/2020/11/Observaciones-MIATM_PODER-enviado-a-Semarnat.pdf 48 Ibíd.
} 
En todos los casos, las herramientas están aprobadas por las autoridades, pero existe una fuerte disputa social en ellas. Las discusiones se centran en torno a una falaz dicotomía respecto a la necesidad de generar oportunidades laborales para la población o conservar la naturaleza, cuando esta condición no debería ser contrapuesta si el modelo que da la fuente de trabajo no es extractivista.

El turismo se ha vinculado históricamente al incremento del desarrollo, entendiendo al desarrollo como un proceso más allá del crecimiento económico, donde se puede obtener beneficios sociales de diferentes dimensiones ${ }^{49}$; es por ello la importancia de la ampliación del concepto de desarrollo y su vinculación con la sostenibilidad. La actividad turística ${ }^{50} 51$, en sus diversas formas, ha ido respondiendo a los desafíos que se fueron presentando; en este sentido, la OMT manifestó y definió los principios para el turismo sostenible ${ }^{52}$, sumando posteriormente los 17 Objetivos del Desarrollo Sostenible, los que fueron incorporados en muchas propuestas turísticas, lo cual generó el fortalecimiento en movimientos locales que han ido haciendo frente a los cambios en pos de conservar sus modos de vida, cultura y actividades. Es así que, el desafío se presenta al momento de establecer el grado de cumplimiento de los 17 objetivos y la escala de impacto de estos. Más aún, cuando autores como Cardoso jiménez, Castillo Nechar y Hernández Vega ${ }^{53}$, además, cuestionan la raíz de la sostenibilidad.

En este marco, se interpela al turismo masivo, a los sistemas turísticos y el rol que juegan en el mecanismo dominante, llenando las playas de plásticos y saturando los sistemas sanitarios y energéticos de los lugares de destino. Las nuevas propuestas de la OMT, como la «Iniciativa Mundial sobre Turismo y Plástico ${ }^{54}$, plantean pequeños pasos para mejorar las condiciones; no obstante, todavía es necesario sumar la vinculación humanidad-naturaleza, donde el humano no sea un elemento ajeno, sino como parte de la naturaleza, cuestionando los modelos de desarrollo que en cada territorio se dan.

En palabras de Boullón ${ }^{55}$, las alternativas turísticas son tan diversas como personas en el mundo, a diferencia, el planeta es finito en condiciones naturales

\footnotetext{
${ }^{49}$ Analía Almirón, Rodolfo Bertoncello, Diego Kuper y Lucas Ramírez. «El turismo como impulsor del

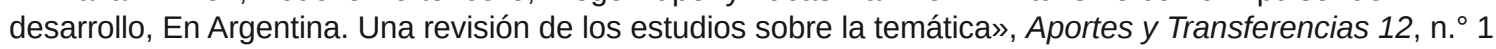
(2008): 57-86.

50 Simplificando al turismo como la acción del desplazamiento de su lugar de origen, por un plazo menor a un año, para ocio individual o colectivamente; sin embargo la definición se encuentra abierta a una mayor profundidad, siendo el abordaje interdisciplinaria del mismo el que mejor podrá definirlo.

51 Daniel Nicolas Hiernaux, «¿Cómo definir el turismo? Un repaso disciplinario», Aportes y Transferencias 6, n. ${ }^{\circ} 2$ (2002): 11-27. http://nulan.mdp.edu.ar/258/.

52 World Tourism Organization, «Sustainable Tourism for Development Guidebook - Enhancing Capacities for Sustainable Tourism for Development in Developing Countries», Sustainable Tourism for Development Guidebook - Enhancing Capacities for Sustainable Tourism for Development in Developing Countries (Madrid: World Tourism Organization (UNWTO), January 1, 2013), https://doi.org/10.18111/9789284415496

53 Carlos Cardoso Jiménez, Marcelino Castillo Nechar y Cárlos Hernández Vega, «Sosteniendo al turismo o turismo sostenible», Estudios y perspectivas en turismo 23 (2014): 376-395, https://www.redalyc.org/pdf/ 1807/180730867009.pdf

54 World Tourism Organization, «Iniciativa Mundial Sobre Turismo y Plásticos, OMT», Iniciativa Mundial sobre turismo y plásticos, 2020, https://www.unwto.org/es/desarrollo-sostenible/iniciativa-mundial-turismo-plasticos 55 Roberto Boullón, Planificación del espacio turístico (México: Trillas, 2006).
} 
y es un elemento determinante que debe ser incorporado a dichas propuestas. En este sentido, el ecoturismo surgió como alternativa para las lógicas que predominan al interior de la actividad turística y se consolidaba como una ambivalencia; el generar desarrollo y bienestar económico, pero sin degradar dicha fuente de recursos para extenderlo en el tiempo. La propuesta ecoturística se plantea desde diferentes autores como un turismo de contemplación de la naturaleza, uno de sus objetivos es la menor intervención en la naturaleza ${ }^{56}$. El turismo de naturaleza presenta una visión de lo que se espera respecto a las actividades turísticas, donde el cuidado y conservación son esenciales ${ }^{57}$; en cambio, no vislumbran indicios de un cambio de perspectiva, por lo tanto, el ecoturismo da un paso más allá, esperando que el turista busque una alternativa, que la función de su desarrollo turístico permita un cambio en su vida y en el lugar donde realiza la actividad turística. Visión que se particulariza si se considera lo afirmado en la Declaración de Québec sobre el ecoturismo ${ }^{58}$, evento que estableció principios rectores para minimizar los impactos en el ambiente e incentivar el respeto a las culturas locales.

El contexto de pandemia que presentó el COVID-19 puso en jaque al turismo en todas sus formas, puso en evidencia la importancia de un cambio en los modelos dominantes de producción y de relación con la naturaleza, las modificaciones en los ecosistemas atentan contra los complejos procesos que suceden en estos, dejando sin perspectivas sobre los posibles escenarios a futuro, por lo cual, el respeto y convivencia con la naturaleza son fundamentales ${ }^{59}$ para realizar nuevamente una actividad turística.

\section{Conclusiones}

De acuerdo con lo expuesto, resulta importante identificar que los procesos históricos y culturales no son ajenos a los naturales, ya que la humanidad es parte de esa naturaleza. Su proceso de crecimiento ha ido mutando con el tiempo; pero, lamentablemente, en su gran mayoría fue en detrimento de esta. Sin querer concluir, el análisis que se presenta en este artículo de los conceptos enunciados, son un primer esbozo de los planteos que como sociedad y especie se debe realizar, particularmente al predominar modelos dominantes que direccionaron e impulsaron determinadas herramientas para evaluar las perturbaciones, pero que no pudieron dar respuestas a la altura de la complejidad del sistema. Es así que la humanidad como elemento constitutivo de la naturaleza es clave para determinar los marcos conceptuales desde los

\footnotetext{
56 Unión Internacional para la Conservación de la Naturaleza, UICN, «Turismo, áreas protegidas y comunidades. Estudios de caso y lecciones aprendidas del Programa de parques en peligro 2002-2007», 2007, https://www.portalces.org/sites/default/files/turismo_y_comunidades.pdf

57 Violante Martínez Quintana, «El turismo de naturaleza: Un producto turístico sostenible», Arbor 193, n. ${ }^{\circ}$ 785 (2017), https://doi.org/10.3989/arbor.2017.785n3002

58 World Tourism Organization (UNWTO), «Québec Declaration on Ecotourism Déclaration de Québec Sur l'écotourisme Declaración de Quebec Sobre El Ecoturismo» (Madrid, 2002), https://doi.org/10.18111/ unwtodeclarations.2002.12.02.

${ }^{59}$ Alejandro Mantecón, «La crisis sistémica del turismo: Una perspectiva global en tiempos de pandemia», en Turismo Pos-COVID-19. Reflexiones, retos y oportunidades, Cátedra de Turismo, 19-29 (Canarias: Universidad de La Laguna , 2020), https://doi.org/https://doi.org/10.25145/b.Turismopos-COVID-19.2020
} 
cuales se construye para vincularse. El análisis de los orígenes filosóficos como sociales y matemáticos demuestran el fraccionamiento de la percepción de la naturaleza y del ser humano como especie.

La complejidad de los sistemas naturales, así como las interacciones con la actividad turística, entre otras, merece ser profundizada a la vista de las consecuencias de las acciones humanas, tal como se visualizó durante la pandemia por el COVID-19, que, si bien no se puede analizar en retrospectiva, será una advertencia que se debe analizar para la construcción de nuevos modos de entendimiento de la relación ser humano-naturaleza. Conjuntamente, se debe plantear alternativas a los modelos dominantes de desarrollo que respeten los límites de un planeta finito.

La identificación de las perturbaciones, por parte de los actores implicados en el desarrollo de la actividad turística, no puede ser negada. Bajo determinados parámetros, resulta factible la mitigación de las perturbaciones, una reducción a su mínimo posible en un contexto dado, pero para ello resulta primordial comprender al turismo no solo como una mera actividad económica que debe de priorizar los criterios de rentabilidad, sino que debe velar por la sostenibilidad de los entornos naturales, entendiendo las dimensiones que lo componen.

Diversos paradigmas expuestos pueden aportar una mirada enriquecedora desde otras realidades sociales, incluyendo la diversidad cultural, cosmovisiones ancestrales, protegiendo los ecosistemas y propiciando un uso racional de los recursos naturales. El turismo, en última instancia, deberá ser un partícipe indispensable en algunas regiones para reflejar y potenciar la identidad zonal y cultural, sin imponer mecanismos de vida distintos a lo local; de esta manera, el turista pueda interiorizarse con diferentes valores desde una perspectiva distinta, impulsando encuentros entre culturas en un marco de respeto.

Las herramientas analizadas, así como los documentos, demostraron que se cuenta con iniciativas desde propuestas internacionales y locales, pero es evidente que no son suficientes los esfuerzos para resolver los problemas generados, esto en parte como una consecuencia del marco del cual partieron.

Resulta imperioso la constante reflexión de los «modos de hacer» las prácticas y proyectos turísticos, con la identificación de aquellas construcciones que fueron en comunión con las comunidades y la naturaleza para revalorizarlas, reduciendo aquellos impactos negativos que violan los valores culturales y ambientales de los pueblos locales, de allí la necesidad de interpelar las herramientas que se utilizan para abordar las problemáticas y los proyectos que vinculen ser humano-naturaleza.

Finalmente, la búsqueda de alternativas que relacionen teoría y práctica tendiente a una construcción y necesaria deconstrucción crítica como ejercicio en vistas de un abordaje más holístico, es un ejercicio constante que no invalida las acciones individuales y colectivas en el quehacer por un ambiente natural y social más sano. 


\section{Formato de citación según APA}

Guzmán, L. A., Tuninetti, L. E. y Mizdraje, D. (2022). Relación de la humanidad con la naturaleza, las perturbaciones y el turismo. Revista Espiga, 21(43), 40-61.

Formato de citación según Chicago-Deusto

Guzmán, L. Ana, Luis E. Tuninetti y Dafne Mizdraje. «Relación de la humanidad con la naturaleza, las perturbaciones y el turismo». Revista Espiga 21, n. 43

(enero-junio, 2022): 40-61. 


\section{Referencias}

Almirón, Analía, Rodolfo Bertoncello, Diego Kuper y Lucas Ramírez. «El turismo como impulsor del desarrollo, En Argentina. Una revisión de los estudios sobre la temática». Aportes y Transferencias 12, n. ${ }^{\circ} 1$ (2008): 57-86.

Baldi López, Graciela y Eleonora García Quiroga. "Calidad de vida y medio ambiente. La psicología ambiental». Universidades (México, DF), n. ${ }^{\circ} 30$ (2005): 9-16, https://biblat.unam.mx/es/revista/universidades-mexico-d-f/ articulo/calidad-de-vida-y-medio-ambiente-la-psicologia-ambiental

Barrera Constanza y Romina Bahamondes. «Turismo sostenible: Importancia en el cuidado del medio ambiente». RIAT: Revista Interamericana de Medioambiente y Turismo 8, n. ${ }^{\circ} 1$ (2012): 50-56, https://dialnet.unirioja.es/ servlet/articulo?codigo $=4052116 \&$ info $=$ resumen\&idioma $=$ ENG

Benítez, Jorge A. y M. Alexander Shelley. «Evaluación ambiental estratégica (preliminar) del proyecto Tren Maya». Acceso: 18 de enero de 2022. https:// www.researchgate.net/publication/331558425

Biosafety Unit. «Metas de Aichi para la diversidad biológica». Secretariat of the Convention on Biological Diversity, November 5, 2018. https://www.cbd.int/ sp/targets/

Boullón, Roberto. Planificación del espacio turístico. México: Tillas, 2006.

Butler, Richard William. «The Concept of Carrying Capacity for Tourism Destinations: Dead or Merely Buried?». Progress in Tourism and Hospitality Research 2, n. ${ }^{\circ}$ 3-4 (1996): 283-293. https://doi.org/10.1002/ PTH.6070020309

Cardoso Jiménez, Carlos, Marcelino Castillo Nechar y Carlos Hernández Vega. «Sosteniendo al turismo o turismo sostenible». Estudios y perspectivas en turismo 23 (2014): $376-395 . \quad \mathrm{https}: / / \mathrm{www}$. redalyc.org/pdf/ $1807 / 180730867009 . p d f$

Christophe Bonenfant, Jean-Michel Gaillard, Tim Coulson, Marco Festa-Bianchet, Anne Loison, Mathieu Garel, Leif Egil Loe, Pierrick Blanchard, Nathalie Pettorelli, Norman Owen-Smith, Johan Du Toit y Patrick Duncan. «Chapter 5 Empirical Evidence of Density-Dependence in Populations of Large Herbivores». Advances in Ecological Research 41 (2009): 313-357. https:// doi.org/10.1016/S0065-2504(09)00405-X 
Clavijo Flórez Isabel y Daniel Castrejón. «Análisis sobre la protección y garantía del derecho humano a un medio ambiente sano en la región sureste mexicana». Ciudad de México, July 30, 2020. https://poderlatam.org/wpcontent/uploads/2020/11/Observaciones-MIATM_PODER-enviado-aSemarnat.pdf

Dachary Alfredo A., Maris Stella César y Burne Arnaiz. «Turismo masivo o alternativo: Los límites de la sustentabilidad», Terra Mundus $1, \mathrm{n}^{\circ} 1$ (2014). http://dspace.uces.edu.ar:8180/jspui/handle/123456789/2870

De Sousa Santos, Boaventura. «La cruel pedagogía del virus». Ed. María Fernanda Pampín et al., Clacso, 2020, Buenos Aires. https://bibliotecarepositorio.clacso.edu.ar/bitstream/123456789/15543/1/La-cruelpedagogia-del-virus.pdf

Echamendi Lorente, Pablo. «La capacidad de carga turística. Aspectos conceptuales y normas de aplicación». Anales de Geografla de la Universidad Complutense 21 (2001): 11-30. https://www.ucm.es/data/cont/ media/www/pag-49173/2001_Artículo Echemendi_Teoría (ANALES).pdf

Escobar, Arturo. «Territorios de Diferencia: La ontología política de los derechos al territorio». En: Cartografías de la paz: una mirada crítica al territorio, comp. Diego Andrés Mora Arenas, Natalia Sánchez Corrales, Bogotá: Ediciones Unisalle, 2014 (Colombia, 2010). https://ciencia.lasalle.edu.co/ cgi/viewcontent. cgi?article $=1005 \&$ context $=$ catedra_lasallista $\#$ page $=108$

Escobar, Arturo. La invención del Tercer Mundo: Construcción y deconstrucción del desarrollo. Caracas: Editorial El perro y la rana, 1998.

Figueroa, Juana R. «El hombre, clave fundamental en el desarrollo». Espacio Abierto 15, n. ${ }^{\circ} 3$ (2006): 597-616. https://www.redalyc.org/pdf/ 122/12215306.pdf

Flores Asenjo, María Pilar y María C. Parra Meroño. «Indicadores de capacidad de carga del turismo». Revista de investigación en turismo y desarrollo local 3, n. $^{\circ} 8$ (2010): 1-15.

García, Rolando. Sistemas complejos, conceptos, método y fundamentación epistemológica de la investigación interdisciplinaria. Barcelona: Gedisa, 2006.

García Hernández, María. «Turismo y Medio Ambiente. En Ciudades históricas. De la capacidad de acogida turística a la gestión de los flujos de visitantes». Anales de Geografía de La Universidad Complutense (2000): 131-148. https://core.ac.uk/download/pdf/38823161.pdf 
Gómez Orea, Domingo, Mauricio Gómez Villarino y Alejandro Gómez Villarino. Evaluación ambiental estratégica. Madrid: Mundi-Pren, 2014.

Gudynas, Eduardo. «Diez tesis urgentes sobre el nuevo extractivismo. Contextos y demandas bajo el progresismo sudamericano actual». En Extractivismo, política y sociedad, 187-225. Quito: Centro Andino de Acción Popular y Centro Latino Americano de Ecología Social, 2009, 187-225.

Hardin, Garrett. «The Tragedy of the Commons». Science 162, 1968.

Harvey, David. «Razones para ser anticapitalistas». Ed. María Fernanda Pampín et al., Clacso, 2020, Buenos Aires. https://www.tni.org/files/publicationdownloads/razones_para_ser_anticapitalistas_david_harvey_clacso.pdf

Hernández Sampieri, Roberto, Carlos Fernández Callado y Pilar Baptista Lucio. Metodología de la investigación. Ciudad de México: McGraw Hill, 2014.

Hiernaux, Daniel Nicolas. «¿Cómo definir el turismo? Un repaso disciplinario». Aportes y Transferencias 6, n. 2 (2002): 11-27. http:// nulan.mdp.edu.ar/258/

Infobae. «Tren Maya: El gran impacto ambiental que dejará a su paso el proyecto insignia de AMLO». 2020. https://www.infobae.com/america/mexico/ 2020/08/24/tren-maya-el-gran-impacto-ambiental-que-dejara-a-su-paso-elproyecto-insignia-de-amlo/

Informe de Brundtland 'Our Common Future', 1987. https://web.archive.org/web/ 20111201061947/http://worldinbalance.net/pdf/1987-brundtland.pdf

Intergovernmental Science-Policy Platform on Biodiversity and Ecosystem Services (IPBES), 2019. «Summary for Policymakers of the Global Assessment Report on Biodiversity and Ecosystem Services». Bonn, Edición en PDF. https://doi.org/10.5281/ZENODO.3553579

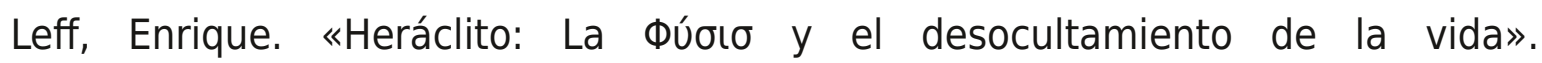
Cosmotheoros. Revista Internacional de Epistemología Ambiental 1 (2020): 1-38.

Leff, Enrique. «Saber Ambiental: Sustentabilidad, Racionalidad, Complejidad, Poder». Ciudad de México: Siglo XXI (2002): 414.

Lovelock, James. «La venganza de la Tierra. La teoría de Gaia y el futuro de la humanidad». Buenos Aires: Planeta, 2007. 
Madrid Casado, Carlos M. «Historia de la teoría del caos contada para escépticos: Cuestiones de génesis y estructura». Ed. Encuentros Multidisciplinares 34 (2010): 1-15. https://repositorio.uam.es/handle/10486/679228

Manfred Lenzen, Ya-Yen Sun, Futu Faturay, Yuan-Peng Ting, Arne Geschke y Arunima Malik. «The Carbon Footprint of Global Tourism» Nature Climate Change n. ${ }^{\circ} 6$ (2018): 522-28, https://doi.org/10.1038/s41558018-0141-x

Mantecón, Alejandro. «La crisis sistémica del turismo: Una perspectiva global en tiempos de pandemia». En Turismo Pos-COVID-19. Reflexiones, retos y oportunidades. Cátedra de Turismo, 19-29. Canarias: Universidad de La Laguna, 2020. https://doi.org/https://doi.org/10.25145/b.TurismoposCOVID-19.2020

Martínez Quintana, Violante. «El turismo de naturaleza: Un producto turístico sostenible». Arbor 193, n. ${ }^{\circ} 785$ (2017). https://doi.org/10.3989/ arbor.2017.785n3002

Naess, Arne. Une Écosophie Pour La Vie. Introductión à l'écologie Profonde. Du Seuil (París, 2017).

Nieto, Margarita, Luisa Fernanda Cardona y Catherine Agudelo. Servicios ecosistémicos: Provisión y regulación hídrica. En Los páramos. Bogotá: Instituto Bogotá, 2015.

Odum, Eugene P. Ecología. México: Interamericana, 1972.

Ortiz Blanco, Mercedes Adriana. «La relación hombre-naturaleza. Tendencias de su filosofar en Cuba». Revista de Ciencias Sociales, n. ${ }^{\circ} 32$ (Chile, 2014): 63-76. https://www.redalyc.org/pdf/708/70831715004.pdf

Osorio García, Maribel. «Turismo masivo y alternativo. Distinciones de la sociedad moderna/posmoderna». Convergencia. Revista de Ciencias Sociales 17, n. ${ }^{\circ}$ 52 (2010): 235-260. http://www.scielo.org.mx/pdf/conver/v17n52/ v17n52a10.pdf

Pardón Acosta, Jorge y Dariel Bermúdez. «De las 'Ciencias Duras' y las 'Ciencias Blandas». Revista Caribeña de Ciencias Sociales, n. ${ }^{\circ}$ 2019-10 (2019): 1-12. https://www.eumed.net/rev/caribe/2019/10/ciencias-duras-blandas.html

Pérez-García, José Nicolás. "Causas de la pérdida global de biodiversidad». Revista de la asociación colombiana de ciencias biológicas 1, n. 32 (2020): 183-98. https://doi.org/10.47499/revistaaccb.v1i32.219 
Programa de las Naciones Unidas para el Medio Ambiente. «Cambio climático y turismo: Responder a los retos mundiales», 2007. Declaración de Davos. https://www.ucipfg.com/Repositorio/MGTS/MGTS14/MGTSV-CC/modulo2/ Declaracion_de_Davos._Cambio_Climatico_y_Turismo.pdf

Rodríguez Caro, Roberto Carlos. «Estudios sobre los efectos de las perturbaciones ambientales en poblaciones animales mediante métodos analíticos y de simulación». Universidad Miguel Hernández, 2017. http://dspace.umh.es/bitstream/11000/5170/1/ Tesis Rodriguez-Caro\%2C Roberto Carlos.pdf; E.P.

Rodríguez Martínez, Francisco. «El impacto ambiental del turismo». En Andalucía, Simposio Hispano-Francés Desarrollo Regional y Crisis Del Turismo, 1994.

Romero, Gilberto y Andrew Maskrey. «Como entender los desastres naturales en los desastres no son naturales». En Los desastres no son naturales, ed. Red de estudios sociales en prevención de desastres en América Latina, 1993, 140. https://repositorio.gestiondelriesgo.gov.co/bitstream/handle/ 20.500.11762/19762/

LosDesastresNoSonNaturales\%28Maskrey_1993\%29.pdf? sequence $=1$ \&isAllowed $=\mathrm{y}$

Toledo, Víctor M. «Repensar la conservación: ¿Áreas naturales protegidas o estrategia bioregional?». Gaceta Ecológica, n. ${ }^{\circ}$ 77, 2005. https:// www.redalyc.org/pdf/539/53907705.pdf

Unión Internacional para la Conservación de la Naturaleza. «Turismo, áreas protegidas y comunidades. Estudios de caso y lecciones aprendidas del Programa de parques en peligro 2002-2007», 2007. https:// www.portalces.org/sites/default/files/turismo_y_comunidades.pdf

Vera Rebollo, José Fernando. «Planificación y gestión del desarrollo turístico sostenible: Propuestas para la creación de un sistema de indicadores». Ed. Instituto Universitario de Geografía Universidad de Alicante. (Alicante, 2001). https://rua.ua.es/dspace/bitstream/10045/20506/1/ Planificacion_gestion_sostenible_desarrollo_turistico_sostenible.pdf

World Tourism Organization. «Iniciativa Mundial Sobre Turismo y Plásticos, OMT». Iniciativa Mundial sobre turismo y plásticos, 2020. https://www.unwto.org/ es/desarrollo-sostenible/iniciativa-mundial-turismo-plasticos 
World Tourism Organization. «Sustainable Tourism for Development Guidebook Enhancing Capacities for Sustainable Tourism for Development in Developing Countries». Sustainable Tourism for Development Guidebook Enhancing Capacities for Sustainable Tourism for Development in Developing Countries. Madrid: World Tourism Organization, UNWTO, 2013. https://doi.org/10.18111/9789284415496.

World Tourism Organization (UNWTO). «Québec Declaration on Ecotourism Déclaration de Québec Sur l'écotourisme Declaración de Quebec Sobre El Ecoturismo». Madrid, 2002. https://doi.org/10.18111/ unwtodeclarations.2002.12.02

Zaffaroni, Eugenio Raúl. La Pachamama y el humano. Buenos Aires, Colihue, Madres de Plaza de Mayo, 2011. 